\title{
Design of Pelletizing Machine (Balling Disc)
}

\author{
K. O. Ikebudu, Chukwumuanya E. O., Swift O. N. K., and Nwokeocha Toochukwu
}

\begin{abstract}
This work presents the design of pelletizing machine for the production of pellets from a mixture either in its powder or molten form. This idea came up during the process of producing pellets for the purpose of strength measurements of powder agglomerates/pellets for good handling of powder materials for usage and during transportation. The machine consist a mixer. This machine is mainly found in production industries, railway/coal corporations and steel industries.
\end{abstract}

Index Terms-Pelletizing machine, pellets, agglomerates.

\section{INTRODUCTION OF DESIGN}

Palletizing machine is specialized equipment. It is used for pelletizing of powder materials into pellets.

It is original and peculiar with large scale disc-pellet machine and designed on the basis of the large scale discpellet machine that is used in industries like iron and steel industry, chemical industry, pharmaceutical industry, cement industry, ceramics industry, railway corporations, seen in metallurgical workshops and some related industries. This machine adapts to pelletizing many kinds of powder material provided it is mixed with a particular solvent.

The rotation disk is automatic and raw material collection and granulating capacity will be higher. The disc balling machine is used in the balling granular used to make damp granule into antique pellets. [1]-[3]. It is equally used in the palletizing and alkaline leaching of powdery low grade zinc oxide ores [4]. It is also used in the mines.

Disc balling granulator is suitable for mixing material pelletizing equipment with nutrient [5]. It has the following advantages:

1) High balling rate

2) Big roundness intensity of particles

3) Visual operation and easy for maintenance.

They are of different kinds and forms ranging from its sizes, shapes, method of operation (manual or automatic), capacity, function, etc.

\section{A. Types of Pelletizing Machine}

1) Pelletizing machine (Balling disc): Balling disc machine is mainly used for production of balls and agglomerates pellets.

2) Floating feed pellet machine: This type of pelletizing machine is used for production of feed for animals.

3) Wood pellets machine: This type of palletizing machine is used for making pellets of wood, plastics etc.

4) Biomass pellet machine: This type of palletizing

Manuscript received October 22, 2013; revised April 19, 2014.

K. O. Ikebudu and Swift O. N. K. are with the Anambra State University, Uli, Nigeria (e-mail: ikbuduk@yahoo.com).

Chukwumuanya E. O. and Nwokeocha Toochukwu are with the Nnamdi Azikiwe University, Awka, Anambra State, Nigeri. machine is used for producing pellets from biomass.

\section{B. Pelletization}

Pelletization [6] is the unit operation of producing larger bodies from fine powders so as to alleviate many of the problems associated with fine particulates, for example, some of the benefits provided by pelletizing coal include;

1) Improved fugitive dust control

2) Decrease in transportation costs and losses

3) Reduced risk of spontaneous usage

Only partial understandings of the fundamentals of powder material pillarization exist in this project. In this project, we attempted to design palletizing machine for understanding of engineering material handling.

\section{DESIGN SigNIFICANCE}

Poor handling of coal has affected the iron and steel industries, Railway Corporation and coal industries. However, the contemporary palletizing machine is so expensive that some industries in Nigeria cannot afford the price. With the design of pelletizing machine to form pellets as the case maybe, for good handling of powder material, there will be improved fugitive dust control, decrease in transportation costs and losses, reduction in the risk of coal freezing and lowered risk of spontaneous combustion/ usage [6].

\section{DESIGN ANALYSIS}

Considering the single phase induction motor with a speed of $400 \mathrm{rpm}$, having a power of $1800 \mathrm{kw}$, the diameter of the shaft from the motor is $20 \mathrm{~mm}$.

To calculate the angular velocity of the motor;

$$
\begin{gathered}
W=2 \pi N \div 60=(2 \times 3.142 \times 400) \div 60 \\
W=41.89 / \mathrm{sec}
\end{gathered}
$$

To find the actual torque of the motor

$$
\text { Torque }(T)=P / W
$$

where

$$
\begin{aligned}
& P=1800 \times 1000 \\
& W=41.89 \\
& T=1800 \times 10^{3} \times 1000 / 41.89=42 \\
& \text { Again to calculate for the tor } \\
& T=P \times 60 / 2 \Pi \mathrm{n} \\
& T=1800 \times 1000 \times 60 / 2 \pi \times 400 \\
& T=108000000 / 2513.3 \\
& T=42971.835 \mathrm{~N} / \mathrm{m}
\end{aligned}
$$$$
T=1800 \times 10^{3} \times 1000 / 41.89=42969.7 \mathrm{KN} / \mathrm{m}
$$$$
\text { Again to calculate for the torque transmitted }
$$

\section{Material Selection}

One of the basic factors that affect the choice of a project is the availability of materials, selection of materials, and 
the cost of the materials for the design or fabrication of the project. The materials selection for the design function depends on the following;

- The availability of these materials in our local markets.

- The strength of these materials

- The cost of these materials

- The possession of simple mode of the operation

- The appearance of these materials

- The ability of these materials to serve the purpose for which the project is intent to be designed.

\section{A. Materials}

Metallic gears

Electric motors (single phase)

Angle iron

Stainless Disc $(25 \mathrm{~cm})$

Fasteners (bolts and nuts)

Washers

Shaft

Vibration Pad

Cream hardeners

Citizen gloss paint (army green)

Hand grinding machine

Hand drilling machine

Welding machine

Sand paper

Chisel

Hammer

Scriber

Try square

Bench vice

Hack saw

Flat file

Hand Glove

Welding goggle

\section{DESIGN OF KeY}

The key [7] is made of mild steel used in the locking of the gear to the motor shaft. It is inserted between the shaft and the hub of the gear acting as the pulley to connect both the gear and the shaft together in other to prevent relative motion between them. It is also inserted parallel to the axis of the shaft. The name of the key used in this design is square sunk key.

Mathematically,

$$
W=T=D / 4
$$

where,

$W=$ width of the key

$T=$ Thickness of the key

$D=$ Diameter of the key

$D=20 \mathrm{~mm}$

$W=T=20 / 4=5 \mathrm{~mm}$

NB: A key way which is a slot or recess in the shaft from the motor and the hub of the gear acting as the pulley to accommodate the key made. Basically keys are used as temporary fasteners and subjected to consider crushing and shearing stresses.

Also note that during the design of the key, forces due to fit of the key where neglected and it was assumed that the distribution of forces along the length of the key is uniform. Now owing to the fact that

$$
\begin{aligned}
L \times W \times T \times d / 2 & =L \times t / 2 \times \sigma c \times d / 2 \\
w / t & =\sigma c / 2 T
\end{aligned}
$$

where

$W=$ width of the key

$T=$ Thickness of the key

$\sigma c=$ crushing stress of the key

$\tilde{l}=$ Shearing stress of the key

Therefore the key used in this design is equally strong in shearing and crushing. Know that the key material and shaft material are the same.

To find the speed of the driven $N 2$

From $T 2=N 1 T 1 / N 2$

$N 2=N 1 T 1 / T 2$

where,

$T 1=$ no of teeth of drivers $=24$

$T 2=$ no of teeth of driven $=24$

$1=$ speed of driver $=400$

$N 2=$ speed of driven $=200$

Mean speed $=400+200 / 2=300 \mathrm{rpm}$

$N=300 \mathrm{rpm}$

$N 2=400 \times 24 / 24=400 \mathrm{rpm}$

$N=300 \times 24 / 24=300 \mathrm{rpm}$

Therefore, if $N 1=N 2$

$T 1=T 2$

This means that gears transmits equal amount of speed. The name of the gear is spur gear, with $50 \mathrm{mmdiameter}$ as pitch circle.

$$
D p=m T p
$$

To find the modulus

$50 / 24=m$

$M=2.08$

\section{A. Design of Step Turned Shaft}

The shaft used in this design is called a transmission shaft. Now assuming the allowable shear stress as $42 \mathrm{mpa}$ the line shaft is rotating at $400 \mathrm{rpm}$ and transmitting $18 \mathrm{kw}$.

To find the diameter of the shaft

$T=p \times 60 / 2 \pi N=18 \times 10^{3} \times 60 / 2 \pi \times 400$

$=429.69=430 \mathrm{~N}-\mathrm{m}$ or

$=430 \times 10^{3} \mathrm{~N}-\mathrm{mm}$

But $T=\pi / 16 \times \tau \times d^{3}$

$430 \times 10^{3}=\pi / 16 \times 42 \times d$

$430 \times 10^{3} / 16=\pi 42 d^{3}$

$203.65=d$

$d=5.8 \mathrm{~mm}$

NB: we assumed $20 \mathrm{~mm}$ diameter of the shaft because of its rigidity and loading.

\section{Methodology}

\section{A. Marking out}

The first stage of this fabrication is the marking out of the required dimensions of the sheet metal and the angle iron together with the square iron bars [8].

\section{B. Cutting process}

The second stage after the required dimensions is marked 
out the cutting out of the required length from the main material will take place. The cutting out is done on the vice with the aid of a hacksaw.

\section{Welding Process}

After the first two processes is carried out, the materials are joined together by means of the joining process called "WELDING". This involves the welding of the various parts of the frame together using the electric arc welding process.

\section{Boring Process}

After the welding process, holes are bored into the frame to accommodate the bolts and nuts that will be used to fasten the machine parts together.

\section{E. Coupling Process}

This comprises the coupling of the various parts of the machine which include the induction motor, the stainless pan, the shaft, the gear train.

\section{F. Filler Process}

This involves the process of filling the various holes and uneven surfaces on the machine with a filler material which is strengthened by a cream hardener.

\section{G. Painting Process}

This is the final process of the work which involves the painting of the machine surface with oil base paint. The painting is done with the aid of a spray-painting machine.

\section{Design Assembly of Pelletizing Machine}

The marking out process, cutting process, welding process, Boring process, coupling process, filling process, Painting processes will be done with the required precision. The joint parts of the Machine will be fastened with the appropriate fasteners. During the assembling, a damper rubber will be used to seal through the edges of the stainless pot including the cover to avoid material loss when the machine is functioning. Due to vibration by the electric motor inside the machine when at work or in operation, the use of a vibration pad will be introduced at the base to control and reduce the vibration effect of the machine. At the end of the assembling operation metal casing will be formed to encapsulate the machine itself to avoid the exposure of the skeletal parts. This metal casing will also be used to make the machine fanciful and presentable. The metal casing will provide support and stability to the machine which will help the machine to stand on its own without falling to any direction. This enclosure will be perforated to aid cooling of the electric motor.

\section{SCHEMATIC REPRESENTATION OF THE PELLETIZING MACHINE}

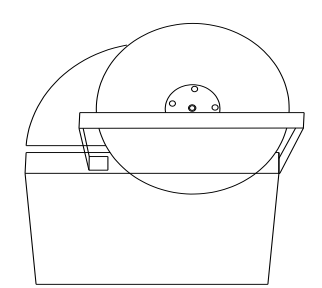

Fig. 1. The front view of the balling disc machine.

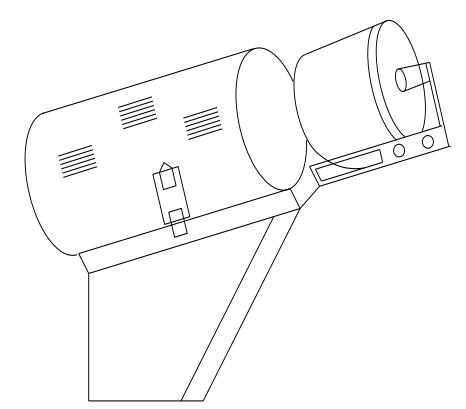

Fig. 2. The side view of the balling disc machine.

\section{DISCUSSION OF DESIGN}

From the result of the experiment performed, it is observed that the balling disc machine produced different sizes range $6-25 \mathrm{~mm}$ of coal pellets. The world grows daily in terms of engineering and technology. Virtually all the machines in the world today have risen from electrically operated to automatically operated. This advancement leads to an effort made on this project to practicalize a simple way of understanding the balling disc technique. The understanding of the balling disc technique is now one of the basic things a designer should know before embarking on designing any machine or manufacturing set up. Hence, it will be of greater advantage to engineering students and respective industries to adopt this balling technique because the world is so much depending on them. This machine, mechanized balling disc (palletizer) for industrial development in Nigeria has been designed, constructed, completed, tested and found worthy to help the affected industries and as a teaching aid for students of engineering to appreciate the manufacturing process being taught them in class room lectures.

\section{Designed Safety PRecaution}

Eye protection is a primary safety consideration around the machine shop. Machine tools produce metal chips and there is always a possibility that these may be ejected from the machine at a high velocity thereby causing serious damage to the body. Eye protector must be worn at all times in the machine shop. Several types of eye gadgets are available but in the course of carrying out the project work we used the plain safety glasses that are available in most shops to prevent the chips from flying into my eyes during the machining of the shaft.

In as much as the machine shop does not present too great a hazard to the feet. However, there is always a possibility that something could drop on one's feet. That was why in the cause of the fabrication we ensured that we wore boots with steel toes as a shield to resist impacts, should a heavy object fall towards my foot.

In an industrial production area or shop there is always a great level of noise due to the equipment's used. we considered the noise level and tried to reduce it to the barest minimum with the use of ear and head helmet.

As a result of the operation done with the grinding machine. It is only but usual that a lot of fine particle grinding dust mixed with metal particles would be produced. The grinding work done to smoothen out some parts of the 
machine was done in open area where there was rapid flow of air.

In the cause of welding we ensured that we wore coveralls to protect skin from the fire sparks coming out due to welding.

\section{Designed MaInTEnANCE}

It is a well-known fact and an act of responsibility to know how to care and maintain machine. Without this maintenance culture amongst us, there would be nonparallel waste of resources in order to procure new machines and whole lots of recyclable waste. In the fabrication of the balling disc machine, the care and maintenance of the machine was highly considered and an easy maintenance culture was included.

The stainless pan was provided with holes in the base and attached to the shaft with bolts and nuts to ensure easy removal for cleaning. Various types and sizes of bolts, nuts and washers were used extensively throughout the system to ensure easy assembling and disassembling and to facilitate easy cleaning.

In the care of the gears, a reasonable amount of grease should be applied to the gear train so as to facilitate easy movement of the gear.

The wire connected to the electric motor to the power supply should be checked often to see if there is an internal snap in the wire or if the wire is about to cut.

The frame of the machine should be dusted frequently and should not be allowed to be exposed to water. The machine should not be used as an alternative to a seat. The machine should never be overloaded.

\section{DESIGNED RECOMMENDATION}

This machine has been designed, fabricated and tested. It is working effectively and conveniently. The project is of benefit and as a teaching aid.

Consequently, from this benefit, the machine is recommended to manufacturers for usage. More importantly, this machine is recommended to scholars for further research and improvement.

\section{CONCLUSION}

The result of the balling disk machine showed good formation of agglomerates balls / pellets diameter from 6 $25 \mathrm{~mm}$. Basically, it is seen mostly in industries like iron and steel industry, chemical industry, pharmaceutical industry, cement industry, ceramics industry, railway corporations, seen in metallurgical workshops and some related industries.

\section{REFERENCES}

[1] Drying product. [Online]. Available: http://www.busytrad.com/

[2] Drying product. [Online]. Available: http://www.chinadrying/products/gpc_15.ph

[3] Drying product. [Online]. Available http://www.khm.com.cn/english/qita/manufacture/qita_cq.php

[4] Science Direct. [Online]. Available: http://www.sciencedirect.com

[5] Disc balling granulator. [Online]. Available: http://www.jderusher.com/product/ypzlg.htm

[6] K. V. S. Sastry, "Reporting period," University of California, College of Engineering," Department of Materials Science and Mineral Engineering, Berkeley, CA 94720.

[7] R. S Khurmi and J. K Gupta, Machine Design, Eurasia Publishing House, 2005

[8] Z. Marcinak, J. L. Duncan, and S. J Hu, Mechanics of Sheet Metal Forming, $2^{\text {nd }}$ edition, ScienceDirect, 2002

K. O. Ikebudu is working as a lecturer in the Anambra State University, Uli, Nigeria. He was born in Nigeria in the year 1981. He has bagged his B.Eng, M.Eng and presently a Ph.D candidate. His research interest is focused on design and production engineering.

E. O. Chukwumuanya is working as a lecturer in the Nnamdi Azikiwe University, Awka, Anambra State, Nigeria. He was born in Nigeria. He has bagged his B.Eng, M.Eng and presently a Ph.D candidate. His research interest is focused on industrial production engineering.

O. N. K. Swift is working as a lecturer in the Anambra State University, Uli Campus, Anambra State, Nigeria. He was born in Nigeria. He has bagged his B.Sc, M.Eng and presently a Ph.D candidate. His research interest is focused on industrial manugacturing engineering.

Nwokeocha Toochukwu is working as a technologist in the Nnamdi Azikiwe University, Nigeria. He was born in Nigeria. He has bagged his B.Eng, and presently an M.Eng candidate. His research interest is focused on design and industrial production engineering. 